\title{
Successful endoscopic treatment of massive bleeding related to the appendiceal stump
}

A 43-year-old man was admitted to the hospital with a 2-day history of rectal bleeding. His medical history included uncomplicated appendectomy 7 days previously because of acute phlegmonous appendicitis. Physical examination findings were normal. Hemoglobin concentration was $7.8 \mathrm{~g} / \mathrm{dL}$ (normal range 13.6$17.2 \mathrm{~g} / \mathrm{dL}$ ) and other laboratory tests showed unremarkable findings. Emergent colonoscopy was performed after blood transfusion and bowel preparation with polyethylene glycol. Colonoscopy revealed much fresh blood in all the colonic lumen and wall but no evidence of any inflammatory lesion or mass. No active bleeding was observed from the terminal ileum, but there was some reflux of fresh blood from the cecum to the terminal ileum. Intermittent bleeding from the appendiceal orifice was identified ( $\bullet$ Fig. 1 ). Endoscopic hemostasis was performed using hemoclips (EZ Clip; Olympus, Tokyo, Japan) and successful hemostasis was confirmed ( Fig.2). The patient was discharged 4 days after the colonoscopic clipping, and was doing well at follow-up. Gastrointestinal hemorrhage from the appendiceal stump after appendectomy is extremely rare. The bleeding may drain into the abdominal cavity, the retroperitoneum, or the digestive tract. The cause of bleeding is usually a small intramural branch of the appendiceal artery at the appendiceal stump [1]. Appendiceal bleeding may be treated by endoscopic procedures, percutaneous transcatheter arterial embolization, or surgical cecal resection [2]. Angiographic embolization can cause complications such as necrosis of normal mucosa and perforation [3]. Endoscopic procedures such as epinephrine injection, heat coagulation, or argon plasma coagulation carry some risk of bowel microperforation [4]. For these reasons, we preferred endoscopic clipping, and achieved successful hemostasis.

Endoscopic clipping can be used to treat appendiceal stump bleeding effectively and safely, thus avoiding emergent surgery.

Endoscopy_UCTN_Code_CCL_1AD_2AF

Competing interests: None

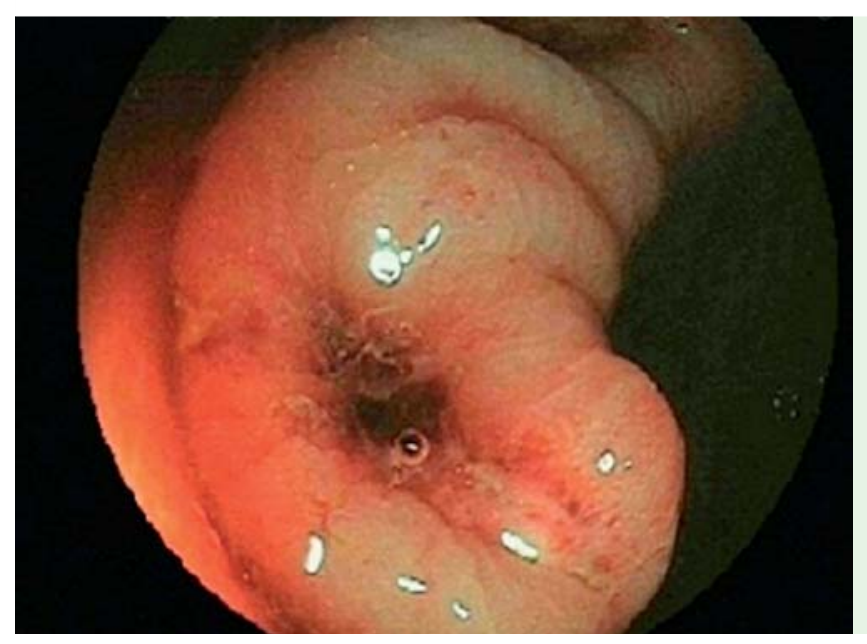

Fig. 1 Intermittent bleeding from the appendiceal orifice in a 43-year-old man.

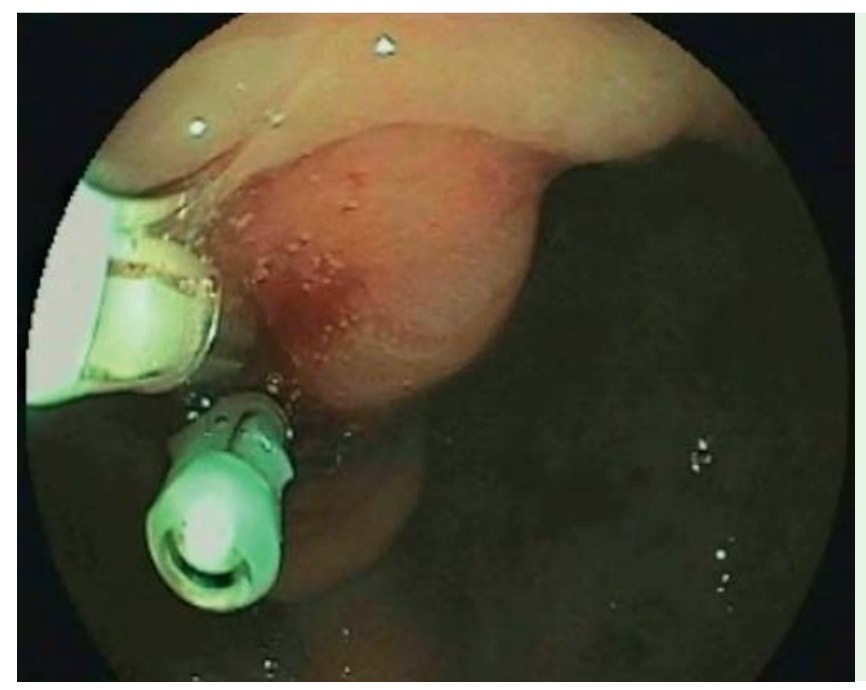

Fig. 2 Endoscopic hemostasis was successfully achieved using two clips.

\section{Z. Simsek, F. Karaahmet, O. Yuksel, B. Yılmaz, S. Coban}

Department of Gastroenterology, Dışkapı Yıldırım Beyazıt Educational and Research Hospital, Ankara, Turkey

\section{References}

1 Vo N, Hall FM. Severe postappendectomy bleeding. Am Surg 1983; 49: 560-562

2 Zitt M, Klaus A, Kirchmayr W et al. Colonoscopically placed hemoclips as treatment for massive appendiceal stump bleeding. Surg Endosc 2003; 17: 1677-1678

3 Kyokane T, Akita Y, Katayama M et al. Angiodysplasia of the appendix. Am J Gastroenterol 2001; 96: 242-244

4 Park I, Kwon CI, Ko KH et al. Colonoscopic clipping as a treatment for appendiceal bleeding. Gut Liver 2010; 4: 411-414
Bibliography

Dol http://dx.doi.org/ 10.1055/s-0032-1326115 Endoscopy 2013; 45: E15 (c) Georg Thieme Verlag KG Stuttgart · New York ISSN 0013-726X

Corresponding author

\section{F. Karaahmet, MD}

Department of Gastroenterology

Dışkapı Yıldırım Beyazıt Educational and Research Hospital

06080 Altındag-Ankara

Turkey

Fax: +90-312-3186690

fatih_ares@yahoo.com.tr 